\title{
Risk factors and secondary care utilisation in a primary care population with non-tuberculous mycobacterial disease in the UK
}

\author{
Eleanor L. Axson ${ }^{1}$ (D) $\cdot$ Navdeep Bual $^{1} \cdot$ Chloe I. Bloom $^{1} \cdot$ Jennifer K. Quint ${ }^{1}$
}

Received: 13 August 2018 / Accepted: 8 October 2018 / Published online: 27 October 2018

(C) The Author(s) 2018

\begin{abstract}
Prior research has identified risk factors associated with developing non-tuberculous mycobacterial disease (NTMD); we identified risk factors and secondary care utilisation of NTMD patients in the UK. This was a matched case-control study using electronic healthcare records from Clinical Practice Research Datalink from 2006 to 2016. NTMD was defined using prescription data and Read codes, based on international guidelines. Risk factors for NTMD were investigated using conditional logistic regression within a representative general population. All-cause secondary care utilisation (combined inpatient, outpatient, emergency visits) was investigated for participants with linked Hospital Episode Statistics (HES), using incidence rate ratio (IRR) from 2007 to 2015. We identified 1225 individuals with NTMD. A subset of individuals (426 patients) were eligible for linkage with HES. In the adjusted model, risk factors most strongly associated with an increased likelihood of NTMD included previous tuberculosis (OR 69.0; 47.7-99.8); bronchiectasis (OR 23.3; 12.4-43.9); lung cancer (OR 14.9; 3.98-55.7); oral corticosteroids (OCS; OR 7.28; 4.94-10.7); immunosuppressive (excluding corticosteroids) medication (OR 3.05; 1.15-8.10); being underweight (odds ratio (OR) 2.92; 95\% CI 1.95, 4.36); and rheumatoid arthritis (OR 2.12; 1.05-4.27). NTMD patients had significantly higher rates of all-cause secondary care utilisation than non-NTMD patients (IRR 5.80; 5.14-6.46). Using a representative adult population, we identified prior TB, bronchiectasis, lung cancer, immunosuppressive medication, and OCS as the risk factors associated with the highest odds of developing NTMD in the UK. Patients with NTMD experienced nearly six times more all-cause secondary care events following their NTMD diagnosis than patients without NTMD.
\end{abstract}

Keywords Epidemiology $\cdot$ Risk factors $\cdot$ NTM $\cdot$ COPD $\cdot$ Bronchiectasis

\section{Background}

Non-tuberculous mycobacterium (NTM) are naturally occurring bacteria ubiquitous in the environment, found in water and soil [1]. There is great geographic variation in NTM species [2], and, while NTM do not normally cause disease, highrisk populations have been identified [3, 4]. Disease from NTM (NTMD) can manifest throughout the body, but pulmonary infections are the most common [5].

Established risk factors for NTMD include low body fat [6], bronchiectasis [7], and history of tuberculosis (TB) [3].

Eleanor L. Axson

e.axson@imperial.ac.uk

1 Respiratory Epidemiology, Occupational Medicine and Public Health, National Heart and Lung Institute, Imperial College London, London SW3 6LR, UK
While immunosuppression is accepted as a risk factor [8], studies have yet to tease out the role of diseases - such as rheumatoid arthritis (RA) [9], chronic obstructive pulmonary disease (COPD) [3, 10], and asthma [11] — as opposed to their treatments - such as inhaled corticosteroids (ICS) and oral corticosteroids (OCS) [3, 10]. Additionally, some studies have found higher proportions of NTMD patients being current or former smokers, having gastroesophageal reflux disease (GORD), chronic kidney disease (CKD), and lung cancer [11].

Previous studies have also highlighted that patients with NTMD utilise greater secondary care resources than those without NTMD, with Germany seeing a 5.9\% increase per year in NTMD-related hospitalisations from 2009 to 2014 [12] and a US study finding NTMD patients at a greater risk of hospitalisation [13]. Healthcare expenditure for NTMD patients is significantly higher than for those without NTMD, placing noteworthy burden on healthcare systems $[12,13]$.

This is the first study to examine risk factors and secondary care utilisation for NTMD patients in a representative UK 
adult population using primary care records. Additionally, we examine both risk factors and secondary care utilisation in a subpopulation of patients with underlying chronic respiratory diseases (CRDs) including asthma, bronchiectasis, COPD, cystic fibrosis (CF), and interstitial lung disease (ILD).

\section{Methods}

\section{Data source}

The Clinical Practice Research Datalink (CPRD) provides access to detailed, anonymised primary care records for $6.8 \%$ of the UK population, shown to be representative of the UK population in terms of sex, BMI, and ethnicity [14]. Linkage of CPRD data with Hospital Episode Statistics (HES) is available for $\sim 75 \%$ of practices in England [14]. HES datasets provide data from inpatient, outpatient, and accident and emergency (A\&E) attendance including patient demographics, diagnoses, admission, and discharge [15].

\section{Defining NTMD}

The identification of people with NTMD included antimycobacterial prescription data and Read codes - a form of clinical classification describing patient conditions, medications, and diagnoses - for NTMD between 01/01/2006 and 31/ 12/2016. The cohort comprised patients with evidence of appropriate treatment/monitoring of NTMD as determined by international guidelines for the treatment and management of NTMD $[5,16,17]$. Patients must have met the following criteria [18]:

1. Have $3+$ NTM sputum samples sent $\geq 3$ months apart over 2 years;

OR

2. Be taking a guideline-recommended $[5,16,17]$ multidrug regimen with $3+$ consecutive prescriptions within 100 days of each other;

\section{OR}

3. Be taking $\geq 2$ drugs with $3+$ consecutive prescriptions within 100 days of each other identified from guidelines as being used to treat NTMD $[5,16,17]$ that must include at least one of (a) isoniazid, (b) ethambutol, or (c) rifampicin/ rifabutin in combination with isoniazid or ethambutol.

Due to the nature of coding in CPRD, it was not possible to identify infection location and thus we refer to NTMD not NTM lung disease though we suspect the majority of patients have NTM in the lungs.

\section{Defining the study populations}

Our population consisted of all identified NTMD cases matched $1: 6$ on sex, age (5 years), and general practice to randomly selected controls from the CPRD population (Fig. 1). We also investigated a subpopulation (CRD subpopulation) of NTMD cases with underlying CRD also matched 1:6 on sex, age (5 years), and general practice to randomly selected controls from the CPRD population with CRD (Fig. 1). CRD included asthma, bronchiectasis, CF, COPD, and ILD. Asthma [19] and COPD [20] patients were identified using validated algorithms. The Read codes used to identify bronchiectasis [21], ILD [22], and CF [18] patients have been published. In both populations, cases and controls were matched on the index date, the first date of NTMD, for the case.

\section{Demographics}

We included age (years), sex (male/female), and smoking status (never/not recorded, former, and current). Body mass index $\left(\mathrm{BMI} ; \mathrm{kg} / \mathrm{m}^{2}\right)$ was divided into underweight $(<18.5)$, healthy weight (18.5-24.9), overweight (25.0-29.9), and obese $(>=30)$.

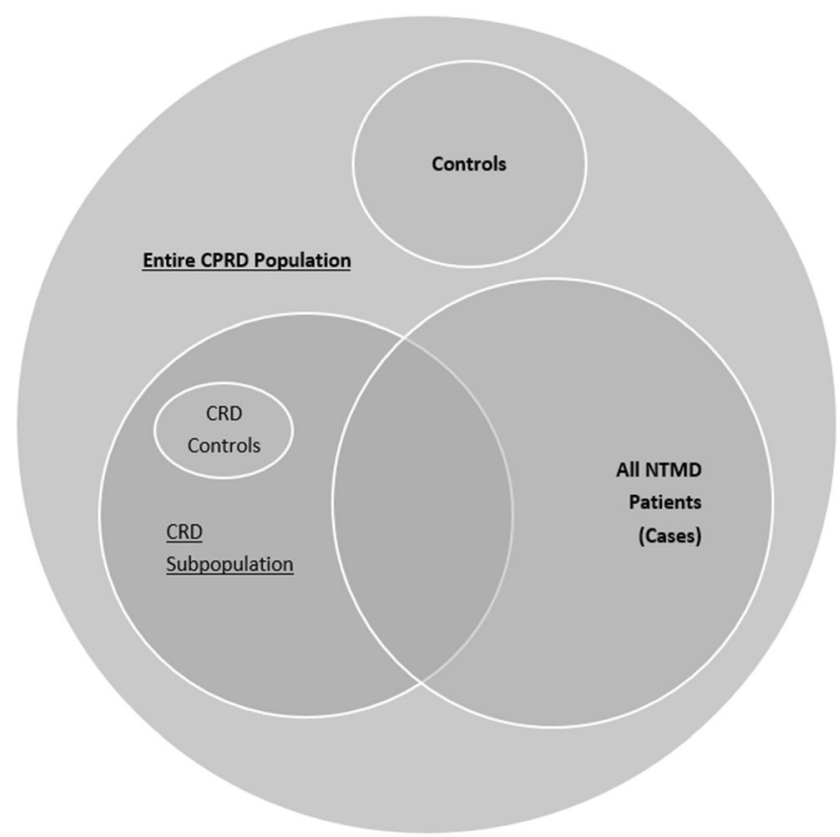

Fig. 1 Defining the study populations. All cases and controls were adults aged 18+, whose practice data was deemed to be 'up-to-standard' for research purposes by CPRD. Start of follow-up was defined as the latest of (1) study start (01/01/2007); (2) patient's 18th birthday; (3) patient's current record date; (4) practice's 'up-to-standard' date; or (5) the index date of the case. End of follow-up was defined as the first of (1) study end (31/12/2015); (2) patient's last record collection date; (3) patient transferring out of practice; or (4) patient death 


\section{Analysis of risk factors}

Risk factors were determined using previous literature on NTMD (Table 1; excluding sex and age) [3, 4, 6, 7, 9-11]. Patients could have more than one risk factor and only conditions coded any time prior to the index date were considered risk factors. Current immunosuppressive, ICS, and OCS use were defined as having had $\geq 2$ prescriptions within 6 months of the index date. For chronic conditions, patients were considered to have the condition from the time of the first Read code.
Conditional logistic regression was used to estimate the association between risk factors and incident NTMD. A diseaseonly model included all disease risk factors for NTMD, but no medications. A treatment-adjusted model included all risk factors, both diseases and medications, in order to identify whether diseases or treatment were driving NTMD risk.

\section{Analysis of all-cause secondary care utilisation}

Using a subset of patients with linked HES data available, allcause secondary care utilisation was defined as the cumulative

Table 1 Descriptive statistics for the general population and chronic respiratory disease (CRD) population for cases and controls

\begin{tabular}{|c|c|c|c|c|}
\hline & $\begin{array}{l}\text { NTMD cases } \\
(n=1225)\end{array}$ & $\begin{array}{l}\text { Controls } \\
(n=7308)\end{array}$ & $\begin{array}{l}\text { NTMD cases in CRD } \\
\text { subpopulation }(n=463)\end{array}$ & $\begin{array}{l}\text { Controls in CRD } \\
\text { subpopulation }(n=2764)\end{array}$ \\
\hline Female & $584(47.7)$ & $3504(47.7)$ & $218(47.1)$ & $1308(47.1)$ \\
\hline Mean age \pm SD (years) & $55.2 \pm 18.5$ & $55.2 \pm 18.6$ & $63.6 \pm 14.5$ & $63.6 \pm 14.4$ \\
\hline Males & $55.5 \pm 17.5$ & $55.5 \pm 17.5$ & $62.9 \pm 13.9$ & $62.9 \pm 13.8$ \\
\hline Females & $54.9 \pm 19.7$ & $54.9 \pm 19.6$ & $64.4 \pm 15.1$ & $64.4 \pm 15.1$ \\
\hline \multicolumn{5}{|l|}{ Smoking status } \\
\hline Never smoker/not recorded & $571(46.6)$ & $4073(55.4)$ & $136(29.4)$ & $1163(41.9)$ \\
\hline Current smoker & $327(36.7)$ & $1827(24.9)$ & $145(31.2)$ & $691(24.9)$ \\
\hline Former smoker & $327(36.7)$ & $1450(19.7)$ & $182(39.3)$ & $924(33.3)$ \\
\hline \multicolumn{5}{|l|}{ Body mass index } \\
\hline Underweight $(<18.5)$ & $124(11.1)$ & $151(2.36)$ & $64(14.3)$ & $49(1.83)$ \\
\hline Healthy weight (18.5-24.9) & $533(47.6)$ & $2351(36.7)$ & $232(51.8)$ & $793(29.6)$ \\
\hline Overweight (25.0-29.9) & $312(27.9)$ & $2351(36.7)$ & $106(23.7)$ & $962(36.0)$ \\
\hline Obese $(>=30)$ & $151(13.5)$ & $1550(24.2)$ & $46(10.3)$ & $871(32.6)$ \\
\hline \multicolumn{5}{|l|}{$\mathrm{CRD}$ risk factors } \\
\hline Asthma & $167(13.6)$ & $387(5.27)$ & $138(29.8)$ & $1321(47.6)$ \\
\hline Bronchiectasis & $104(8.49)$ & $25(0.34)$ & $103(22.3)$ & $165(5.94)$ \\
\hline COPD & $232(18.9)$ & $274(3.73)$ & $229(49.5)$ & $1029(37.0)$ \\
\hline Cystic fibrosis & $10(0.82)$ & $<5$ & $9(1.94)$ & $6(0.22)$ \\
\hline Interstitial lung disease & $30(2.45)$ & $29(0.39)$ & $20(4.32)$ & $76(2.74)$ \\
\hline \multicolumn{5}{|l|}{ Other disease risk factors } \\
\hline Chronic kidney disease & $131(10.7)$ & $423(5.76)$ & $33(7.13)$ & $276(9.94)$ \\
\hline Cancer, lung & $17(1.39)$ & $7(0.10)$ & $12(2.59)$ & $15(0.54)$ \\
\hline Cancer, other than lung & $117(9.55)$ & $598(8.14)$ & $59(12.7)$ & $332(12.0)$ \\
\hline Diabetes & $144(11.8)$ & $663(9.02)$ & $51(11.0)$ & $374(13.5)$ \\
\hline Gastroesophageal reflux disease & $156(12.7)$ & $730(9.93)$ & $74(16.0)$ & $449(16.2)$ \\
\hline History of tuberculosis & $518(42.3)$ & $76(1.03)$ & $171(36.9)$ & $54(1.94)$ \\
\hline Rheumatoid arthritis & $40(3.27)$ & $67(0.91)$ & $22(4.75)$ & $55(1.98)$ \\
\hline \multicolumn{5}{|l|}{ Medication risk factors } \\
\hline Immunosuppressive use* & $16(1.31)$ & $35(0.48)$ & $8(1.73)$ & $11(0.40)$ \\
\hline Inhaled corticosteroids & $251(20.5)$ & $409(5.56)$ & $228(49.2)$ & $1137(40.9)$ \\
\hline Oral corticosteroids & $180(14.7)$ & $127(1.73)$ & $125(27.0)$ & $155(5.58)$ \\
\hline
\end{tabular}

Non-tuberculous mycobacterial disease (NTMD). CRD including asthma, bronchiectasis, cystic fibrosis, chronic obstructive pulmonary disease (COPD), and interstitial lung disease

SD standard deviation

Data are presented as number of patients $(\%)$ unless otherwise specified

*Excluding corticosteroids 
number of inpatient stays, outpatient visits, and A\&E attendance from 2007 to 2015 in England. These matched cohort analyses used the populations identified above (Fig. 1). The average incidence rate ratio (IRR) comparing all-cause secondary care utilisation between patients with NTMD to patients without NTMD from 2007 to 2015 was analysed. Similar analysis of mortality was planned, but was unable to be completed due to small numbers of deaths.

All statistical analyses were performed in STATA version 15 (StataCorp LP, College Station, TX, USA).

\section{Results}

\section{Description of study populations}

There were 1225 cases of NTMD identified in the general population and 463 cases identified in the CRD subpopulation from 2006 to 2016 (Table 1). A subset of individuals (426 general; $163 \mathrm{CRD}$ ) were eligible for linkage with HES.

\section{Risk factors for NTMD in the general population}

Results of the crude, disease-only, and treatment-adjusted regression models can be seen in Table 2. Cancers other than lung were not significantly associated with NTMD in any of the models. All other risk factors were significantly associated with increased NTMD in all the models (Table 2).

\section{Risk factors for NTMD in the CRD subpopulation}

Results of the crude, disease-only, and treatment-adjusted regression models in the CRD subpopulation can be seen in Table 3. Asthma, other cancers, diabetes, and GORD were not associated with NTMD in any of the models. COPD and ILD were significantly associated with NTMD in the crude and disease-only models, but lost significance in the treatment-adjusted model. All other risk factors were significantly associated with increased NTMD in all the models (Table 3).

\section{Secondary care utilisation in the general population}

On average, secondary care utilisation was 5.80 (IRR; 95\% CI $5.14,6.46$ ) higher for NTMD patients than non-NTMD patients, from 2007 to 2015 (Fig. 2).

\section{Secondary care utilisation in the CRD subpopulation}

In the CRD subpopulation, average IRR from 2007 to 2015 comparing NTMD patients to non-NTMD patients was 3.26 (95\% CI 2.89, 3.62) (Fig. 2).

\section{Discussion}

This is the first study to assess NTMD risk factors and secondary care burden in the UK using a representative primary care adult population and a CRD subpopulation. Prior TB and bronchiectasis were most strongly associated with NTMD, while medications that suppressed the immune system were also strongly associated.

In this UK primary care population, prior TB was found to be the strongest risk factor; an association with previous TB has also been found in populations from Taiwan [23] and Denmark [3]. Patients with a history of TB may be more likely to have their sputum cultured for mycobacteria, increasing NTMD identification; however, it has also been proposed that post-inflammatory bronchiectasis resulting from TB may account for some increased risk [24].

Bronchiectasis was the most strongly associated CRD with NTMD, as seen elsewhere [3]. Previous research has explored the relationship between bronchiectasis and NTMD and it has been proposed that the two diseases are inextricably linked such that it may not be clear which disease preceded the other [7].

Asthma and ILD were not significantly associated with NTMD in our treatment-adjusted models. The odds of NTMD associated with COPD halved from the disease-only models to the treatment-adjusted models, suggesting the increased risk was in a large part due to COPD treatment. Patients with CRD may experience acute episodes of worsening symptoms, termed exacerbations, which may require additional medication and/or hospitalisation. Exacerbations are often provoked by infections, and treatment given (e.g. antibiotics, OCS) may be detrimental to those with NTM infection. Importantly, it has been shown that NTMD risk increases with increasing number of COPD exacerbations in the year prior to NTMD diagnosis [3]. Exacerbation treatment may similarly be driving risks seen due to asthma and ILD in studies not accounting for treatment $[3,11]$. CRD patients considered to be at risk for NTMD may benefit from screening prior to being prescribed these therapies.

Many previous studies have pointed to immunosuppression as a risk factor for NTMD, including due to immunosuppressive medication [8] and steroids [4]. Immunosuppressive drugs, excluding corticosteroids, were significantly associated with NTMD, though more so in CRD patients. As in previous studies [3, 10], we found that ICS significantly increased odds of NTMD; however, OCS demonstrated an even greater association with NTMD. While ICS was significantly associated with NTMD, most probably by decreasing local immunity [3], immunosuppressive medications and OCS, which decrease systemic immunity, were more strongly associated with NTMD.

RA was significantly associated with NTMD in all models. Previous research has found that RA patients exposed to anti- 
Table 2 Conditional logistic regression models for non-tuberculous mycobacterial disease (NTMD) risk factors in the whole population

\begin{tabular}{|c|c|c|c|}
\hline Crude OR $(95 \%$ CI) & $p$ value & $\begin{array}{l}\text { Model w/o treatments } \\
\text { OR }(95 \% \mathrm{CI})\end{array}$ & $p$ value \\
\hline
\end{tabular}

\begin{tabular}{|c|c|c|c|c|c|c|}
\hline \multicolumn{7}{|l|}{ Smoking status } \\
\hline Never smoker/not recorded & Reference & & Reference & & Reference & \\
\hline Current smoker & $1.30(1.12,1.51)$ & 0.001 & $0.92(0.73,1.17)$ & NS & $0.90(0.71,1.14)$ & NS \\
\hline Former smoker & $1.68(1.44,1.96)$ & $<0.0001$ & $1.30(1.03,1.64)$ & 0.029 & $1.23(0.97,1.57)$ & NS \\
\hline \multicolumn{7}{|l|}{ Body mass index } \\
\hline Underweight $(<18.5)$ & $3.87(2.94,5.10)$ & $<0.0001$ & $2.68(1.81,3.97)$ & $<0.0001$ & $2.92(1.95,4.36)$ & $<0.0001$ \\
\hline Healthy weight (18.5-24.9) & Reference & & Reference & & Reference & \\
\hline Overweight (25.0-29.9) & $0.56(0.48,0.66)$ & $<0.0001$ & $0.62(0.50,0.77)$ & $<0.0001$ & $0.61(0.49,0.76)$ & $<0.0001$ \\
\hline Obese $(>=30)$ & $0.41(0.34,0.52)$ & $<0.0001$ & $0.40(0.30,0.52)$ & $<0.0001$ & $0.40(0.31,0.53)$ & $<0.0001$ \\
\hline \multicolumn{7}{|l|}{ CRD risk factors } \\
\hline Asthma & $2.91(2.39,3.54)$ & $<0.0001$ & $1.80(1.31,2.48)$ & $<0.0001$ & $1.30(0.92,1.85)$ & NS \\
\hline Bronchiectasis & $29.1(18.2,46.5)$ & $<0.0001$ & $25.2(13.7,46.3)$ & $<0.0001$ & $23.3(12.4,43.9)$ & $<0.0001$ \\
\hline COPD & $7.22(5.86,8.89)$ & $<0.0001$ & $4.20(3.04,5.82)$ & $<0.0001$ & $2.47(1.69,3.62)$ & $<0.0001$ \\
\hline Interstitial lung disease & $6.79(3.98,11.6)$ & $<0.0001$ & $3.07(1.30,7.25)$ & 0.011 & $1.97(0.82,4.76)$ & NS \\
\hline \multicolumn{7}{|l|}{ Other disease risk factors } \\
\hline Chronic kidney disease & $2.21(1.76,2.78)$ & $<0.0001$ & $3.21(2.33,4.42)$ & $<0.0001$ & $3.07(2.21,4.27)$ & $<0.0001$ \\
\hline Cancer, lung & $14.6(6.04,35.1)$ & $<0.0001$ & $12.8(3.35,49.1)$ & $<0.0001$ & $14.9(3.98,55.7)$ & $<0.0001$ \\
\hline Cancer, other than lung & $1.22(0.98,1.52)$ & NS & $1.07(0.76,1.51)$ & NS & $1.03(0.72,1.48)$ & NS \\
\hline Diabetes & $1.37(1.12,1.66)$ & 0.002 & $1.59(1.19,2.12)$ & 0.002 & $1.54(1.14,2.08)$ & 0.005 \\
\hline Gastroesophageal reflux disease & $1.35(1.11,1.63)$ & 0.002 & $1.12(0.84,1.50)$ & NS & $1.08(0.80,1.47)$ & NS \\
\hline History of tuberculosis & $66.8(49.2,90.6)$ & $<0.0001$ & $62.3(43.5,89.2)$ & $<0.0001$ & $69.0(47.7,99.8)$ & $<0.0001$ \\
\hline Rheumatoid arthritis & $3.73(2.50,5.57)$ & $<0.0001$ & $4.22(2.32,7.68)$ & $<0.0001$ & $2.12(1.05,4.27)$ & 0.036 \\
\hline \multicolumn{7}{|l|}{ Medication risk factors } \\
\hline Immunosuppressive use* & $2.74(1.52,4.96)$ & 0.001 & & & $3.05(1.15,8.10)$ & 0.026 \\
\hline Inhaled corticosteroids & $4.50(3.78,5.36)$ & $<0.0001$ & & & $1.51(1.07,2.14)$ & 0.020 \\
\hline Oral corticosteroids & $10.4(8.09,13.3)$ & $<0.0001$ & & & $7.28(4.94,10.7)$ & $<0.0001$ \\
\hline
\end{tabular}

Chronic respiratory diseases (CRD) including asthma, bronchiectasis, cystic fibrosis, chronic obstructive pulmonary disease (COPD), and interstitial lung disease

$O R$ odds ratio, $N S$ not significant

Significant $p<0.05$

*Excluding corticosteroids

TNF- $\alpha$ saw increased incidence of NTMD [25]. In our study, the odds of NTMD associated with RA halved from the diseaseonly to the treatment-adjusted model. Immunosuppressive therapy appears to play a significant role in the association of RA and NTMD; however, more studies are needed to determine if $\mathrm{RA}$ itself is a risk factor.

As seen previously, smoking was not significantly associated with NTMD [4] while being underweight was [4, 6]. Unlike previous studies $[4,8]$, we found diabetes increased risk of NTMD. Diabetes has been shown to be a risk factor for TB and likely through similar mechanisms may increase NTMD risk [26]. Previous studies found a higher proportion of CKD [10,11] and GORD [11] in NTMD patients than in controls, but have not examined these as risk factors. CKD was significantly associated with NTMD, but was not significant in CRD patients; while GORD does not appear to be related to any increase in NTMD risk, as seen here and in a US study [8]. Structural damage in the lungs, combined with immunosuppression, may contribute to increased NTMD risk due to lung cancer, but not other cancers. A previous study found increased odds of NTMD with the presence of malignancy [27]; however, it did not break malignancy into types.

On average, following their diagnosis of NTMD, patients experienced nearly six times more all-cause secondary care events than patients without NTMD. This is higher than previous US and German studies, which found that patients with NTMD experience two to three times more hospitalisations, respectively, than general population controls without NTMD $[12,13]$. Neither study investigated secondary care utilisation of NTMD patients with CRDs versus CRD patients without NTMD, meaning bias could have been introduced due to their cases having more $\mathrm{CRD}$ at baseline than their controls. In our 
Table 3 Conditional logistic regression models for non-tuberculous mycobacterial disease (NTMD) risk factors in the chronic respiratory disease (CRD) subpopulation

\begin{tabular}{|c|c|c|c|c|}
\hline Crude OR $(95 \%$ CI) & $p$ value & $\begin{array}{l}\text { Model w/o treatments } \\
\text { OR }(95 \% \mathrm{CI})\end{array}$ & $p$ value & $\begin{array}{l}\text { Model with treatments } \\
\text { OR }(95 \% \text { CI })\end{array}$ \\
\hline
\end{tabular}

\begin{tabular}{|c|c|c|c|c|c|c|}
\hline \multicolumn{7}{|l|}{ Smoking status } \\
\hline Never smoker/not recorded & Reference & & Reference & & Reference & \\
\hline Current smoker & $1.87(1.44,2.43)$ & $<0.0001$ & $1.28(0.87,1.89)$ & NS & $1.25(0.83,1.88)$ & NS \\
\hline Former smoker & $1.75(1.36,2.23)$ & $<0.0001$ & $1.59(1.12,2.25)$ & 0.009 & $1.48(1.02,2.13)$ & 0.037 \\
\hline \multicolumn{7}{|l|}{ Body mass index } \\
\hline Underweight $(<18.5)$ & $5.15(3.30,8.06)$ & $<0.0001$ & $4.59(2.57,8.18)$ & $<0.0001$ & $4.70(2.58,8.55)$ & $<0.0001$ \\
\hline Healthy weight (18.5-24.9) & Reference & & Reference & & Reference & \\
\hline Overweight (25.0-29.9) & $0.35(0.27,0.43)$ & $<0.0001$ & $0.43(0.31,0.59)$ & $<0.0001$ & $0.42(0.30,0.59)$ & $<0.0001$ \\
\hline Obese $(>=30)$ & $0.17(0.12,0.23)$ & $<0.0001$ & $0.22(0.14,0.33)$ & $<0.0001$ & $0.20(0.13,0.30)$ & $<0.0001$ \\
\hline \multicolumn{7}{|l|}{$\mathrm{CRD}$ risk factors } \\
\hline Asthma & $0.81(0.64,1.03)$ & NS & $0.98(0.71,1.35)$ & NS & $0.82(0.58,1.16)$ & NS \\
\hline Bronchiectasis & $6.18(4.58,8.34)$ & $<0.0001$ & $6.63(4.42,9.94)$ & $<0.0001$ & $6.88(4.46,10.6)$ & $<0.0001$ \\
\hline COPD & $2.38(1.91,2.97)$ & $<0.0001$ & $1.74(1.27,2.38)$ & 0.001 & $1.29(0.92,1.82)$ & NS \\
\hline Interstitial lung disease & $2.18(1.29,3.68)$ & 0.004 & $2.66(1.24,5.70)$ & 0.012 & $2.08(0.92,4.73)$ & NS \\
\hline \multicolumn{7}{|l|}{ Other disease risk factors } \\
\hline Chronic kidney disease & $0.66(0.44,0.98)$ & 0.041 & $0.78(0.45,1.33)$ & NS & $0.81(0.46,1.45)$ & NS \\
\hline Cancer, lung & $5.18(2.35,11.4)$ & $<0.0001$ & $9.23(2.99,28.5)$ & $<0.0001$ & $8.83(2.59,30.1)$ & $<0.0001$ \\
\hline Cancer, other than lung & $1.08(0.80,1.47)$ & NS & $0.86(0.54,1.39)$ & NS & $0.89(0.53,1.48)$ & NS \\
\hline Diabetes & $0.79(0.58,1.08)$ & NS & $1.44(0.95,2.19)$ & NS & $1.20(0.76,1.88)$ & NS \\
\hline Gastroesophageal reflux disease & $0.99(0.75,1.30)$ & NS & $1.04(0.71,1.51)$ & NS & $0.92(0.62,1.37)$ & NS \\
\hline History of tuberculosis & $35.2(23.4,52.8)$ & $<0.0001$ & $29.9(18.7,48.0)$ & $<0.0001$ & $36.1(21.7,60.2)$ & $<0.0001$ \\
\hline Rheumatoid arthritis & $2.50(1.50,4.17)$ & $<0.0001$ & $5.41(2.62,11.2)$ & $<0.0001$ & $2.49(1.04,5.97)$ & 0.041 \\
\hline \multicolumn{7}{|l|}{ Medication risk factors } \\
\hline Immunosuppressive use* & $4.36(1.76,10.8)$ & 0.002 & & & $9.23(2.12,40.1)$ & 0.003 \\
\hline Inhaled corticosteroids & $1.46(1.18,1.79)$ & $<0.0001$ & & & $1.52(1.11,2.08)$ & 0.008 \\
\hline Oral corticosteroids & $6.60(5.00,8.70)$ & $<0.0001$ & & & $6.17(4.17,9.13)$ & $<0.0001$ \\
\hline
\end{tabular}

CRD including asthma, bronchiectasis, cystic fibrosis, chronic obstructive pulmonary disease (COPD), and interstitial lung disease

OR odds ratio, $N S$ not significant

Significant $p<0.05$

*Excluding corticosteroids

study, those CRD patients with NTMD experienced over three times more all-cause secondary care events than those CRD patients without NTMD. Demonstrating that having NTMD increases secondary care events regardless of CRD status.

\section{Limitations}

We did not have linked microbiological data therefore misclassification of NTMD was possible. We took a number of steps to ensure that those included were very likely to have NTMD, although it is possible some patients with disease were not included in our study. Firstly, we identified patients taking multi-drug combinations that are guideline-recommended for the treatment of NTMD, as well as patients on other combinations not explicitly recommended, but consisting of recommended drugs $[5,16,17]$. Secondly, we excluded all patients taking any multi-drug regimen for $<3$ months. Thirdly, we excluded patients taking rifampicin in the absence of ethambutol or isoniazid; rifampicin can be used to treat other infections [28] and recommended regimens for NTMD have rifampicin paired with at least one other antimycobacterial $[5,16$, 17]. Lastly, we excluded patients with $<3$ sputum samples sent for NTM as three is the guideline-recommended number of samples to be taken, with at least two of these being positive for diagnosis of NTMD [5, 17]. It is possible that a small number of included patients were being treated with antimycobacterial drugs for other reasons; but, importantly, treatment for latent or active TB is unlikely in primary care [29]. Small numbers prevented analyses of NTMD mortality. As expected, small numbers prevented detailed analyses of CF in our exclusively adult, primary care populations. Cases and controls in the CRD subpopulation were not matched on CRD 
Fig. 2 Annual incidence rate ratios (IRR) for all-cause secondary care utilisation comparing general population (solid) non-tuberculous mycobacterial disease (NTMD) cases to non-cases and chronic respiratory disease $(\mathrm{CRD}$; dashed) subpopulation NTMD cases to non-cases. Secondary care utilisation comprising of inpatient, outpatient, and emergency visits. CRD including asthma, bronchiectasis, cystic fibrosis, chronic obstructive pulmonary disease, and interstitial lung disease. $95 \%$ confidence intervals shown

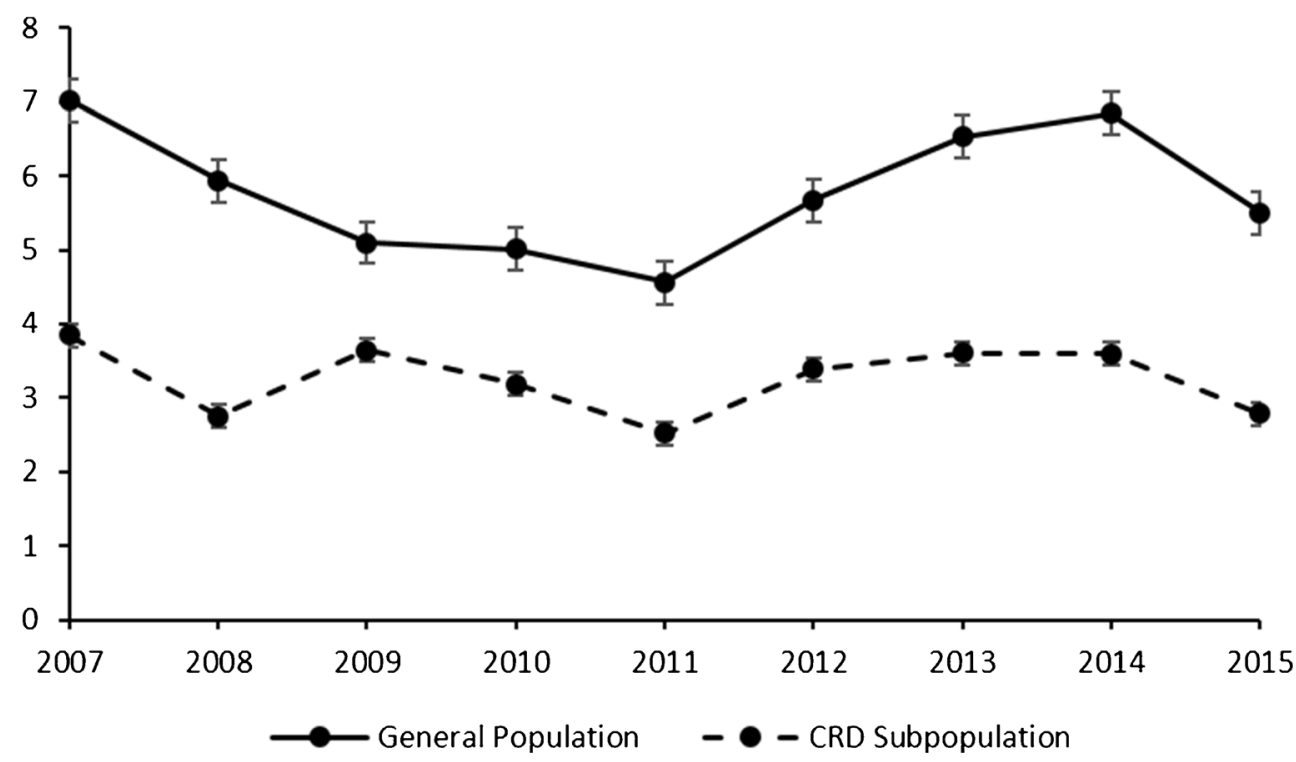

diagnoses, meaning the distribution of CRDs within cases and controls was different and may have led to bias.

\section{Conclusions}

While prospective screening for NTMD is recommended for prior TB [17] and bronchiectasis [30], it is not explicitly recommended for other patients being considered for biologic therapies, including ICS and OCS used in other CRDs. These patients may potentially benefit from further clinical investigations prior to the start of biologic therapies, as these appear to substantially increase the risk of NTMD.

Funding This work was funded by Insmed through a collaborative research agreement between Insmed and Imperial College London.

\section{Compliance with ethical standards}

Conflict of interest Miss Axson, Miss Bual, and Dr. Bloom have nothing to declare. Dr. Quint's research group reports grants and personal fees from Insmed, during the conduct of the study; grants from MRC, grants from Wellcome Trust, grants from British Lung Foundation, grants and personal fees from GSK, grants and personal fees from Boehringer Ingelheim, grants from Royal College of Physicians, personal fees from Chiesi, and personal fees from Teva, outside the submitted work.

Ethical approval The protocol for this research was approved by the Independent Scientific Advisory Committee (ISAC) for MHRA Database Research (protocol number 18_025) and the approved protocol was made available to the journal and reviewers during peer review. Generic ethical approval for observational research using the CPRD with approval from ISAC has been granted by a Health Research Authority (HRA) Research Ethics Committee (East Midlands-Derby, REC reference number 05/MRE04/87). Linked pseudonymised data was provided for this studies by CPRD. Data is linked by NHS Digital, the statutory trusted third party for linking data, using identifiable data held only by
NHS Digital. Select general practices consent to this process at a practice level with individual patients having the right to opt out.

Informed consent No patients were involved in the design or analyses for this study.

Open Access This article is distributed under the terms of the Creative Commons Attribution 4.0 International License (http:// creativecommons.org/licenses/by/4.0/), which permits unrestricted use, distribution, and reproduction in any medium, provided you give appropriate credit to the original author(s) and the source, provide a link to the Creative Commons license, and indicate if changes were made.

\section{References}

1. Falkinham JO (2002) Nontuberculous mycobacteria in the environment. Clin Chest Med 23:529-551

2. Hoefsloot W, van Ingen J, Andrejak C, Angeby K, Bauriaud R, Bemer P, Beylis N, Boeree MJ, Cacho J, Chihota V, Chimara E, Churchyard G, Cias R, Daza R, Daley CL, Dekhuijzen PN, Domingo D, Drobniewski F, Esteban J, Fauville-Dufaux M, Folkvardsen DB, Gibbons N, Gomez-Mampaso E, Gonzalez R, Hoffmann H, Hsueh PR, Indra A, Jagielski T, Jamieson F, Jankovic M, Jong E, Keane J, Koh WJ, Lange B, Leao S, Macedo R, Mannsaker T, Marras TK, Maugein J, Milburn HJ, Mlinko T, Morcillo N, Morimoto K, Papaventsis D, Palenque E, Paez-Pena M, Piersimoni C, Polanova M, Rastogi N, Richter E, Ruiz-Serrano MJ, Silva A, da Silva MP, Simsek H, van Soolingen D, Szabo N, Thomson R, Tortola Fernandez T, Tortoli E, Totten SE, Tyrrell G, Vasankari T, Villar M, Walkiewicz R, Winthrop KL, Wagner D, Nontuberculous Mycobacteria Network European Trials G (2013) The geographic diversity of nontuberculous mycobacteria isolated from pulmonary samples: an NTM-NET collaborative study. Eur Respir J 42(6):1604-1613

3. Andrejak C, Nielsen R, Thomsen VO, Duhaut P, Sorensen HT, Thomsen RW (2013) Chronic respiratory disease, inhaled corticosteroids and risk of non-tuberculous mycobacteriosis. Thorax 68(3):256-262

4. Dirac MA, Horan KL, Doody DR, Meschke JS, Park DR, Jackson LA, Weiss NS, Winthrop KL, Cangelosi GA (2012) Environment 
or host?: A case-control study of risk factors for Mycobacterium avium complex lung disease. Am J Respir Crit Care Med 186(7): 684-691

5. Haworth CS, Banks J, Capstick T, Fisher AJ, Gorsuch T, Laurenson IF, Leitch A, Loebinger MR, Milburn HJ, Nightingale M, Ormerod P, Shingadia D, Smith S, Whitehead N, Wilson R, Floto RA, Group BNGD (2017) British Thoracic Society guidelines for the management of non-tuberculous mycobacterial pulmonary disease (NTMPD). Thorax 72(Supplement 2):ii1-ii64

6. Kartalija M, Ovrutsky AR, Bryan CL, Pott GB, Fantuzzi G, Thomas J, Strand MJ, Bai X, Ramamoorthy P, Rothman MS, Nagabhushanam V, McDermott M, Levin AR, Frazer-Abel A, Giclas PC, Korner J, Iseman MD, Shapiro L, Chan ED (2013) Patients with nontuberculous mycobacterial lung disease exhibit unique body and immune phenotypes. Am J Respir Crit Care Med 187(2):197-205

7. Griffith DE, Aksamit TR (2012) Bronchiectasis and nontuberculous mycobacterial disease. Clin Chest Med 33(2): 283-295

8. Olivier K, Adjemian J, Chou E, Eagle G, Zhang R, Zhang Q (2017) Risk factors and diagnosis of nontuberculous mycobacterial lung disease in incident cohorts of bronchiectasis and chronic obstructive pulmonary disease in a national US managed care insurance plan. 2nd World Bronchiectasis Conference, 6-8 July 2017, Milan, Italy

9. Brode SK, Jamieson FB, Ng R, Campitelli MA, Kwong JC, Paterson JM, Li P, Marchand-Austin A, Bombardier C, Marras TK (2014) Risk of mycobacterial infections associated with rheumatoid arthritis in Ontario, Canada. Chest 146(3):563-572

10. Brode SK, Campitelli MA, Kwong JC, Lu H, Marchand-Austin A, Gershon AS, Jamieson FB, Marras TK (2017) The risk of mycobacterial infections associated with inhaled corticosteroid use. Eur Respir J 50(3)

11. Marras T, Campitelli MA, Kwong JC, Lu H, Brode SK, MarchandAustin A, Gershon A, Jamieson F (2016) Risk of nontuberculous mycobacterial pulmonary disease with obstructive lung disease. Eur Respir J 48(3):928-931

12. Diel R, Jacob J, Lampenius N, Loebinger M, Nienhaus A, Rabe KF, Ringshausen FC (2017) Burden of non-tuberculous mycobacterial pulmonary disease in Germany. Eur Respir J 49(4) https://doi.org/ 10.1183/13993003.02109-2016

13. Marras T, Mirsaeidi M, Chou E, Eagle G, Zhang R, Leuchars M, Zhang Q (2018) Health care utilization and expenditures following diagnosis of nontuberculous mycobacterial lung disease in the United States. J Manag Care Spec Pharm 24(10):964-974

14. Herrett E, Gallagher AM, Bhaskaran K, Forbes H, Mathur R, van Staa T, Smeeth L (2015) Data resource profile: clinical practice research datalink (CPRD). Int J Epidemiol 44(3):827-836

15. Anonymous (2014) Regulatory action and news. WHO Drug Inf 28(1):26-31

16. Campbell I, Drobniewski F, Novelli V, Ormerod P, Pozniak A, Society SotJTCotBT (2000) Management of opportunist mycobacterial infections: joint tuberculosis committee guidelines 1999 . Thorax 55:210-218

17. Griffith DE, Aksamit T, Brown-Elliott BA, Catanzaro A, Daley C, Gordin F, Holland SM, Horsburgh R, Huitt G, Iademarco MF, Iseman M, Olivier K, Ruoss S, von Reyn CF, Wallace RJ Jr, Winthrop K, Subcommittee ATSMD, American Thoracic S,
Infectious Disease Society of A (2007) An official ATS/IDSA statement: diagnosis, treatment, and prevention of nontuberculous mycobacterial diseases. Am J Respir Crit Care Med 175(4):367-416

18. Axson EL, Bloom CI, Quint JK (2018) Nontuberculous mycobacterial disease managed within UK primary care, 2006-2016. Eur J Clin Microbiol Infect Dis 37(9),1795-1803

19. Nissen F, Morales DR, Mullerova H, Smeeth L, Douglas IJ, Quint JK (2017) Validation of asthma recording in the clinical practice research datalink (CPRD). BMJ Open 7(8):e017474

20. Quint JK, Mullerova H, DiSantostefano RL, Forbes H, Eaton S, Hurst JR, Davis K, Smeeth L (2014) Validation of chronic obstructive pulmonary disease recording in the clinical practice research datalink (CPRD-GOLD). BMJ Open 4(7):e005540

21. Quint JK, Millett ERC, Joshi M, Navaratnam V, Thomas SL, Hurst JR, Smeeth L, Brown JS (2016) Changes in the incidence, prevalence and mortality of bronchiectasis in the UK from 2004 to 2013: a population-based cohort study. Eur Respir J 47(1):10-13

22. Dalleywater W, Powell HA, Hubbard RB, Navaratnam V (2015) Risk factors for cardiovascular disease in people with idiopathic pulmonary fibrosis: a population-based study. Chest 147(1):150-156

23. Huang HL, Cheng MH, Lu PL, Shu CC, Wang JY, Wang JT, Chong IW, Lee LN (2017) Epidemiology and predictors of NTM pulmonary infection in Taiwan - a retrospective, five-year multicenter study. Sci Rep 7(1):16300

24. Fujita J, Ohtsuki Y, Shigeto E, Suemitsu I, Yamadori I, Shiode M, Nishimura K, Hirayama T, Matsushima T, Ishida T (2002) Pathological analysis of the cavitary wall in Mycobacterium avium intracellulare complex pulmonary infection. Intern Med 41(8):617-621

25. Brode SK, Jamieson FB, Ng R, Campitelli MA, Kwong JC, Paterson JM, Li P, Marchand-Austin A, Bombardier C, Marras TK (2015) Increased risk of mycobacterial infections associated with anti-rheumatic medications. Thorax 70(7):677-682

26. Marais BJ, Lönnroth K, Lawn SD, Migliori GB, Mwaba P, Glaziou P, Bates M, Colagiuri R, Zijenah L, Swaminathan S, Memish ZA, Pletschette M, Hoelscher M, Abubakar I, Hasan R, Zafar A, Pantaleo G, Craig G, Kim P, Maeurer M, Schito M, Zumla A (2013) Tuberculosis comorbidity with communicable and noncommunicable diseases: integrating health services and control efforts. Lancet Infect Dis 13(5):436-448

27. Lee MR, Yang CY, Shu CC, Lin CK, Wen YF, Lee SW, Ko JC, Wang JY, Lee LN, Yu CJ (2015) Factors associated with subsequent nontuberculous mycobacterial lung disease in patients with a single sputum isolate on initial examination. Clin Microbiol Infect 21(3): 250 e251-250 e257

28. (BNF) BNF. Rifampicin. [Webpage] 2017 [cited 2017 Oct]; Available from: https://bnf.nice.org.uk/drug/rifampicin.html

29. Atchison C, Zenner D, Barnett L, Pareek M (2015) Treating latent TB in primary care: a survey of enablers and barriers among UK general practitioners. BMC Infect Dis 15:331

30. Polverino E, Goeminne PC, McDonnell MJ, Aliberti S, Marshall SE, Loebinger MR, Murris M, Canton R, Torres A, Dimakou K, De Soyza A, Hill AT, Haworth CS, Vendrell M, Ringshausen FC, Subotic D, Wilson R, Vilaro J, Stallberg B, Welte T, Rohde G, Blasi F, Elborn S, Almagro M, Timothy A, Ruddy T, Tonia T, Rigau D, Chalmers JD (2017) European Respiratory Society guidelines for the management of adult bronchiectasis. Eur Respir J 50(3) https://doi.org/10.1183/13993003.00629-2017 